\title{
Métodos avaliativos da aprendizagem no bacharelado na Escola de Enfermagem da Universidade de São Paulo
}

\author{
Daisy Rizatto Tronchin \\ Aisha Negreiros da Costa Pedro \\ Daniele Pereira Rezende
}

RESUMO: O objetivo deste estudo foi analisar os métodos de avaliação descritos nos programas de aprendizagem das disciplinas integrantes da matriz curricular do Projeto Político Pedagógico, implementado em 2010, na Escola de Enfermagem da USP (EEUSP). Pesquisa de abordagem quantitativa e documental, cujos dados foram coletados dos programas de aprendizagem empregando-se um formulário. A coleta de dados ocorreu no mês de agosto, dos anos de 2011, 2012 e 2013 e para análise empregou-se estatística descritiva e inferencial, a um nível de significância de $5 \%$. Dentre os métodos de avaliação predominou na EEUSP a participação em sala de aula e trabalho escrito $(60,4 \%)$ e nas unidades parceiras a prova escrita $(64,7 \%$ com diferença estatística significante. A maior parte das disciplinas ministradas no bacharelado em enfermagem empregou métodos participativos na avaliação, contudo a prova escrita prevaleceu nas unidades parceiras da EEUSP.

Palavras-Chave: Avaliação educacional. Educação superior. Estudantes de enfermagem. Aprendizagem.

Evaluation methods of learning in bachelor's degree in Nursing from the University of São Paulo

\begin{abstract}
The objective of this study was to analyze the evaluation methods described in the learning programs of members of disciplines curriculum of the Pedagogic Political Project, implemented in 2010, at the USP School of Nursing (EEUSP). Research quantitative, descriptive and documentary approach, with data collected employing a form. Data collection took place in August, in the years 2011, 2012 and 2013 and were analyzed using descriptive and inferential statistics, a 5\% significance level. Among the evaluation methods prevailed in EEUSP participation in the classroom and written work $(60.4 \%)$ and partner units the written test $(64.7 \%)$ with significant differences. Most of the subjects taught in the bachelor's degree in nursing employed participatory methods in the evaluation, but the written test prevailed in partner units EEUSP.
\end{abstract}

Key words: Educational evaluation. Higher Education. Nursing students. Learning. 


\section{Introdução}

A avaliação da aprendizagem é uma das facetas do processo de trabalho pedagógico e se constitui em uma atividade do cotidiano da díade docente-discente, repercutindo na qualidade do ensino, da instituição e do profissional.

Consiste em uma temática complexa, do processo educacional, por ser compreendida não como um fim em si mesma, mas sobretudo, como fruto das relações que se estabelecem no processo de sua produção, ao longo dos tempos, imbuída de diversos significados e sentidos (LALUNA; FERRAZ, 2007).

$\mathrm{Na}$ atualidade, a avaliação pode ser entendida como um instrumento de poder relacionado aos domínios sociais representados pela estruturação e pela gestão dos setores educacionais. Nesse aspecto possibilita a reflexão acerca dos determinantes sociais da aprendizagem, além de exercer papel fundamental na direção dos estabelecimentos de ensino, na instituição de ensino, no currículo e em seus programas (BRACCIALLI; OLIVEIRA, 2012).

Constatamos, nas últimas décadas, que as instituições de ensino superior (IES), e, por conseguinte, que a formação de seus profissionais tem sido alvo de discussões e questionamentos acerca dos atributos envolvendo a qualidade do processo educacional, incluindo a avaliação da aprendizagem e a inserção desses profissionais no mundo do trabalho.

Desse modo, é necessário tentar aproximar o conhecimento produzido na universidade às mudanças que se processam na sociedade, com destaque na vida profissional, para que na formação do enfermeiro sejam contemplados os elementos próprios inerentes à profissão e a organização da sociedade (DIAS et al., 2004). Ainda nessa ótica, há que se considerar a valorização dos sujeitos envolvidos no processo ensino-aprendizgem tanto no mundo acadêmico como nos serviços de saúde onde ocorrem as atividades práticas, buscando as potencialidades de cada estudante na construção do conhecimento (FRANCISCO et al., 2016).

Em revisão integrativa realizada por Vasconcelos, Bakes e Gues (2011) constatou-se que grande parte dos cursos de graduação em enfermagem, tanto no Brasil, como na América Latina tem vivenciado reformulações curriculares, sobretudo quanto à concepção metodológica, mantendo-se em segundo plano, questões relativas à avaliação da aprendizagem, seus critérios ou domínios, os quais permanecem pautados nos modelos tradicionais do ensino. 
Nesse cenário, a avaliação da aprendizagem encontra-se intrinsecamente, arraigada à função seletiva dos sistemas educacionais, sobressaindo-se os métodos quantificáveis e classificatórios. Esses métodos, para os professores, despertam questionamentos e sentimentos acerca da qualidade, justiça, integralidade, imparcialidade e honestidade. Para os alunos incute sentimentos como o medo, a insegurança, a humilhação, a ira, a indignação, a desconfiança e a divergência (ANASTASIOU; ALVES, 2009; UNIVERSIDADE DE SÃO PAULO, 2009).

A Escola de Enfermagem da Universidade de São Paulo (EEUSP) no ano de 2002 iniciou o processo de reorientação curricular, culminando com a proposta de um novo Projeto Político Pedagógico (PPP), implementado em 2010.

Assim, o Bacharelado em Enfermagem foi concebido em três ciclos, no qual os módulos que compõem a estrutura curricular são oferecidos de forma articulada pelos quatro Departamentos: de Orientação Profissional, Materno-Infantil e Psiquiátrica, Enfermagem em Saúde Coletiva e Enfermagem Médico-Cirúrgica. Além disso, conta com a participação de várias unidades da USP, nominadas unidades parceiras (UP), cujos docentes ministram disciplinas obrigatórias no currículo, quais sejam: Faculdade de Filosofia, Letras e Ciências Humanas (FFLCH), Faculdade de Medicina (FM), Faculdade de Saúde Pública (FSP), Instituto de Biociências (IB), Instituto de Ciências Biomédicas (ICB), Instituto de Psicologia (IP) e Instituto de Química (IQ).

O Eixo Central do currículo é o Cuidado de Enfermagem, em seus diferentes sentidos, significados e dimensões, ministrado em três ciclos: das Necessidades (1.530h), do Cuidado (1.710 horas) e o da Prática Profissional (920 horas, incluídas as 120 horas do trabalho de conclusão de curso).

Os ciclos encontram-se articulados em torno de eixos integrativos, organizados em semestres compostos por módulos, enfatizando a relação teoria-prática, permitindo a incorporação dos conhecimentos, mediante sua inserção em atividades práticas sob tutoria docente. Esta articulação visa, também, possibilitar a prática da autonomia do estudante por meio da elaboração de projetos de ação aplicados à realidade de saúde experienciada. Para tanto, prioriza metodologias de ensino destinadas ao desenvolvimento do estudante em suas capacidades cognitivas, afetivas e psicomotoras, com vistas à aprendizagem significativa e contínua (UNIVERSIDADE DE SÃO PAULO, 2011; PÜSCHEL, 2011).

Para concluir seu percurso formativo, a partir do $3^{\circ}$ semestre os alunos cursam 10 créditos (150 horas) em disciplinas optativas oferecidas pela EE-USP ou pelas UP da Universidade, no intuito de complementar sua formação do estudante com temas que atendam 
a seus interesses ou necessidades (UNIVERSIDADE DE SÃO PAULO, 2011; PÜSCHEL, 2011).

Diante da reestruturação curricular ocorrida no curso de Bacharelado na EEUSP, culminando com a implementação do PPP em 2010, e acreditando que os achados desta investigação possibilitarão realizar os ajustes necessários nesta nova proposta, no que tange aos métodos de avaliação da aprendizagem dos discentes é que delineamos como objetivos deste estudo: identificar e analisar os métodos de avaliação da aprendizagem descritos nos programas de aprendizagem (PA) das disciplinas obrigatórias e das optativas ministradas no Bacharelado em Enfermagem.

\section{Materiais e métodos}

Trata-se de um estudo quantitativo, descritivo e documental desenvolvido na EEUSP, localizada no Município de São Paulo. Os documentos empregados foram os programas de aprendizagem das disciplinas que integram os três módulos do Curso de Bacharelado em Enfermagem, incluindo aquelas ministradas pelas UP, aprovados, pela Comissão de Graduação da Escola.

Desse modo foram analisados os 37 PA das disciplinas obrigatórias e 23 das optativas, ministradas ao longo dos oito semestres.

A coleta dos dados ocorreu no mês de agosto dos anos de 2011, 2012 e 2013, respeitando-se a aprovação anual das disciplinas pela Comissão de Graduação da EEUSP. O instrumento de coleta foi um formulário contendo os seguintes itens: ano de referência da disciplina, departamento da EEUSP ou unidade da USP ministrante da disciplina, código e nome da disciplina, semestre ministrado e uma legenda com o tipo/método de avaliação descrito em cada PA, a saber: prova escrita em grupo ou individual, prova objetiva (teste), seminário em grupo ou individual, trabalho escrito individual, relatório escrito em grupo, estudo de caso, participação em sala de aula, portfólio, autoavaliação, heteroavaliação, exercícios e outros. Cabe ressaltar, que essa legenda foi elaborada mediante revisão prévia dos PA.

A consulta aos documentos e o preenchimento do formulário foram realizados pela pesquisadora, no Serviço de Graduação da EEUSP.

Os dados foram organizados em planilha eletrônica e analisados com base na estatística descritiva e inferencial. Os testes utilizados para verificar a associação entre os 
métodos de avaliação foram: teste Qui-quadrado ou Exato de Fisher, a um nível de significância de $5 \%$.

O projeto de pesquisa foi aprovado pelo Comitê de Pesquisa da EEUSP - número 145/2011. No sentido de assegurar o anonimato de cada departamento, empregamos letras A, B, C e D. Esclarecemos que algumas disciplinas são ministradas por dois ou mais departamentos, nominadas de disciplinas interdepartamentais.

\section{Resultados}

Os achados apontaram que na matriz curricular as disciplinas obrigatórias encontramse distribuídas de forma equitativa entre a EEUSP $20(54,1 \%)$ e as UP $17(45,9 \%)$; na EEUSP $10(50 \%)$ das disciplinas obrigatórias eram de cunho departamental.

Quanto às disciplinas optativas 7 (30,4\%) foram ministradas pelos Departamentos $\mathrm{C}$ e $\mathrm{D}$, respectivamente e $2(8,7 \%)$ interdepartamentais. No $3^{\circ}$ semestre foi oferecido o maior número de optativas 17 (73,9\%), ocorrendo acentuado declínio nos $5^{\circ}$ e $6^{\circ}$ semestres $1(4,3 \%)$ e não foi ministrado esse tipo de disciplina nos $7^{\circ}$ e $8^{\circ}$ semestres.

Tabela 1 - Distribuição dos métodos de avaliação da aprendizagem, segundo as disciplinas ministradas na EEUSP e nas Unidades Parceiras, São Paulo, 2011- 2013

\begin{tabular}{lrrrrc}
\hline \multirow{2}{*}{ Método de avaliação* } & \multicolumn{2}{c}{ EEUSP } & \multicolumn{2}{c}{ Unidades Parceiras } & \\
& N & \% & N & \% & Valor $\mathbf{~ p}^{\star *}$ \\
\hline Prova & 2 & 4,6 & 5 & 29,4 & $\mathbf{0 , 0 1}$ \\
Prova escrita & 14 & 32,5 & 11 & 64,7 & $\mathbf{0 , 0 4}$ \\
Seminários & 16 & 37,2 & 7 & 41,1 & 0,77 \\
Trabalho escrito & 26 & 60,4 & 5 & 29,4 & $\mathbf{0 , 0 4}$ \\
Estudo de caso & 7 & 16,2 & 1 & 5,8 & 0,420 \\
Participação em sala de & 26 & 60,4 & 4 & 23,5 & $\mathbf{0 , 0 2}$ \\
aula & 5 & 11,6 & 0 & 0 & 0,30 \\
Autoavaliação & 2 & 4,6 & 0 & 0 & 1 \\
Heteroavaliação & 3 & 6,98 & 0 & 0 & 0,551 \\
Portfólio & 2 & 4,6 & 5 & 29,4 & $\mathbf{0 , 0 1}$ \\
Exercícios & 5 & 11,6 & 0 & 0 & 0,30 \\
Frequência & 13 & 30,2 & 2 & 11,7 & 0,19 \\
Outros & & & & & \\
\hline
\end{tabular}

* Uma disciplina pode conter mais de um método de avaliação

** Teste exato de Fisher

*** Outros: avaliação específica e articulada, prova prática em laboratório, frequência, apresentação oral individual, avaliação do conhecimento individual e dramatização.

De acordo com os resultados da Tabela 1, dentre os métodos de avaliação descritos nos PA das disciplinas, na EEUSP predominou o trabalho escrito e a participação em sala de 
aula $26(60,4 \%)$, com diferença estatística significante $\mathrm{p}=0,04$, quando comparados aos empregados pelas UP, onde prevaleceu prova escrita 11 (64,7\%). Podemos verificar, também, que o método exercícios foi utilizado, majoritariamente, 5 (29,4\%) pelas disciplinas ministradas nas UP, com diferença estatística significante. Os métodos autoavaliação 5 $(11,6 \%)$, heteroavaliação $2(4,6 \%)$ e portfólio $3(6,9 \%)$ estiveram presentes nas disciplinas ministradas na EEUSP.

Nos achados do Gráfico 1 estão relacionados os métodos de avaliação considerando as disciplinas obrigatórias, as optativas e as ministradas pelas unidades parceiras.

Gráfico 1 - Distribuição dos métodos avaliação da aprendizagem, segundo as disciplinas obrigatórias e optativas da EE e das Unidades Parceiras, São Paulo, 2011-2013

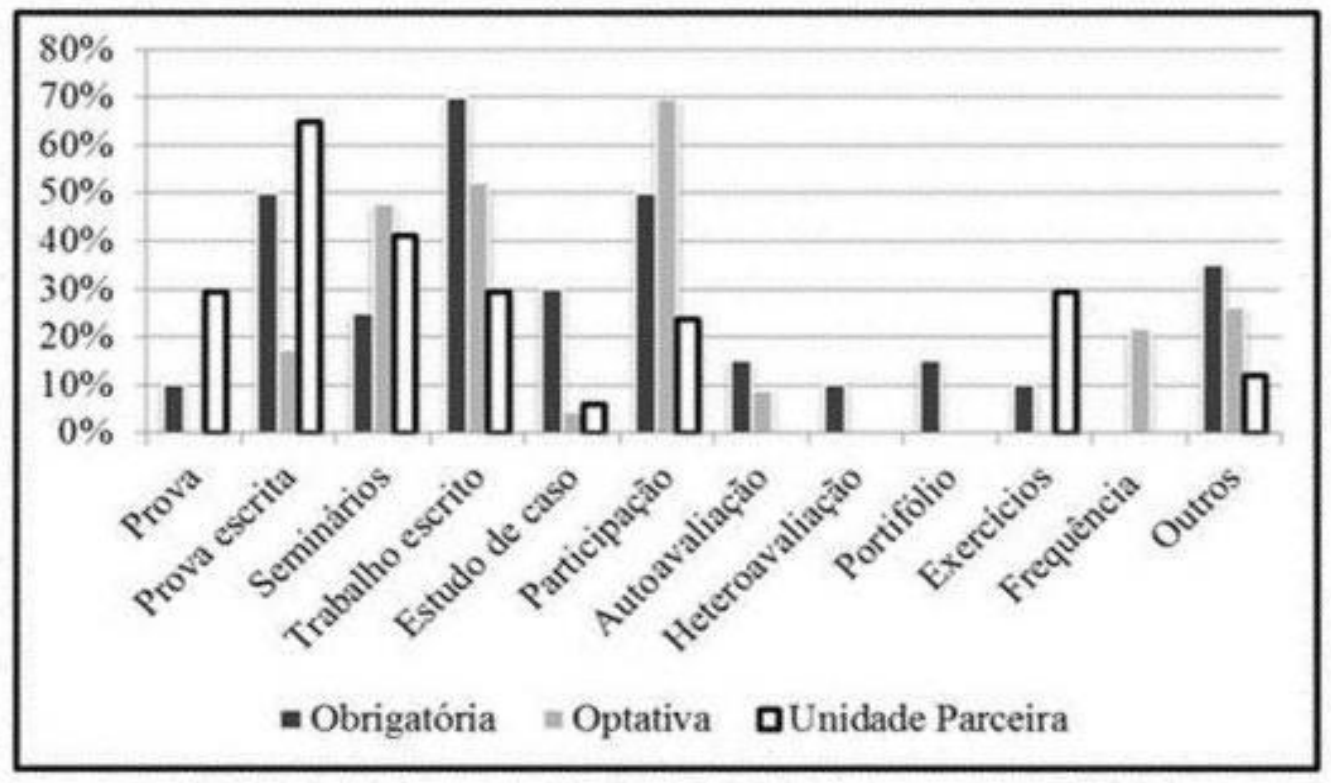

Teste Exato de Fisher: prova $p=0,01$; prova escrita $p=0,04$; participação em sala de aula $p=0,42$ e exercícios $p=0,01$.

Os resultados do Gráfico 1 denotam que nas disciplinas obrigatórias o maior percentual (70\%) foi representado pelo de trabalho escrito, seguido de $50 \%$ pela prova escrita e participação em sala de aula. Por outro lado, nas disciplinas ministradas pelas UP $(64,7 \%)$ dos métodos de avaliação corresponderam a prova escrita, seguido de $41,1 \%$ pelo seminário. Nas disciplinas optativas, a maior parte utilizou a participação em sala de aula, 69,6\%. Notase, ainda, que na Escola de Enfermagem, a autoavaliação $(11,6 \%)$ foi utilizada como método nas disciplinas obrigatórias e optativas, enquanto a heteroavaliação $(4,6 \%)$ e o portfólio $(6,9 \%)$ nas obrigatórias, e a frequência do aluno $(11,6 \%)$ nas optativas.

Cabe ressaltar que, das 17 disciplinas optativas 4 (23,5\%) empregaram a frequência do aluno como método de avaliação. Contudo, esse critério integra no Regimento da 
Universidade, o qual exige $70 \%$ de presença do aluno, não necessitando ser descrito no PA como método de avaliação, uma vez que é um quesito obrigatório para o conjunto das disciplinas.

Tabela 2 - Distribuição dos métodos de avaliação da aprendizagem das disciplinas obrigatórias, segundo cada departamento, EEUSP, São Paulo, 2011- 2013

\begin{tabular}{|c|c|c|c|c|c|c|c|c|c|c|c|c|c|}
\hline \multirow{3}{*}{ Método de Avaliação* } & \multicolumn{13}{|c|}{ Departamentos } \\
\hline & \multicolumn{2}{|c|}{$\begin{array}{c}\text { Inter- } \\
\text { departamental } \\
(\mathrm{N}=10)^{\#}\end{array}$} & \multicolumn{2}{|c|}{$A=(N 2)$} & \multicolumn{2}{|c|}{$B(N=4)$} & \multicolumn{2}{|c|}{$\mathrm{C}(\mathrm{N}=3)$} & \multicolumn{2}{|c|}{$D(N=1)$} & \multicolumn{2}{|c|}{ Total } & \multirow[t]{2}{*}{$\begin{array}{l}\text { P. } \\
\text { valor }^{\star *}\end{array}$} \\
\hline & $\mathrm{N}$ & $\%$ & $\mathrm{~N}$ & $\%$ & $\mathrm{~N}$ & $\%$ & $\mathrm{~N}$ & $\%$ & $\mathrm{~N}$ & $\%$ & $\mathrm{~N}$ & $\%$ & \\
\hline Prova & 1 & 10 & 0 & 0 & 1 & 25 & 0 & 0 & 0 & 0 & 2 & 10 & 0,763 \\
\hline Prova escrita & 3 & 30 & 2 & 100 & 2 & 50 & 3 & 100 & 0 & 0 & 10 & 50 & 0,098 \\
\hline Seminário & 4 & 40 & 0 & 0 & 0 & 0 & 0 & 0 & 1 & 100 & 5 & 25 & 0,165 \\
\hline $\begin{array}{l}\text { Relatório/Trabalho escrito } \\
\text { individual ou em grupo }\end{array}$ & 7 & 70 & 0 & 0 & 4 & 100 & 2 & 66,7 & 1 & 100 & 14 & 70 & 0,161 \\
\hline $\begin{array}{l}\text { Participação nas } \\
\text { atividades programadas }\end{array}$ & 4 & 40 & 1 & 50 & 2 & 50 & 2 & 66,7 & 1 & 100 & 10 & 50 & 0,902 \\
\hline Autoavaliação & 1 & 10 & 1 & 50 & 0 & 0 & 1 & 33,3 & 0 & 0 & 3 & 15 & 0,364 \\
\hline Heteroavaliação & 1 & 10 & 1 & 50 & 0 & 0 & 0 & 0 & 0 & 0 & 2 & 10 & 0,395 \\
\hline Portfólio & 2 & 20 & 0 & 0 & 0 & 0 & 1 & 33,3 & 0 & 0 & 3 & 15 & 0,842 \\
\hline Estudo de caso/ dirigido & 2 & 20 & 0 & 0 & 1 & 25 & 3 & 100 & 0 & 0 & 6 & 30 & 0,071 \\
\hline Exercícios & 1 & 10 & 1 & 50 & 0 & 0 & 0 & 0 & 0 & 0 & 2 & 10 & 0,395 \\
\hline Outros $^{\star \star \star}$ & 6 & 60 & 0 & 0 & 0 & 0 & 0 & 0 & 1 & 100 & 7 & 35 & 0,042 \\
\hline \multicolumn{14}{|c|}{ Uma disciplina pode conter mais de um método de avaliação } \\
\hline
\end{tabular}

A Tabela 2 mostra que o relatório/trabalho individual ou em grupo predominou nas disciplinas obrigatórias 14 (70\%), embora o Departamento A não tenha lançado mão desse tipo de avaliação; a seguir a prova escrita e a participação nas atividades programadas 10 (50\%). O Departamento D não utilizou a prova escrita. Ao compararmos os métodos de avaliação entre os Departamentos verificou-se diferença estatisticamente significante, quanto ao estudo de caso/dirigido (30\%), p=0,07 e outros métodos $(35 \%), \mathbf{p = 0 , 0 4}$.

As disciplinas de cunho interdepartamental apresentaram maior variabilidade em relação aos tipos de avaliação; 100\% dos Departamentos empregaram a participação nas atividades programadas, assim como quatro disciplinas interdepartamentais. 
Tabela 3 - Distribuição dos métodos de avaliação de aprendizagem nas disciplinas optativas, segundo os Departamentos da EEUSP, São Paulo, 2011-2013

\begin{tabular}{|c|c|c|c|c|c|c|c|c|c|c|c|c|c|}
\hline \multirow{3}{*}{$\begin{array}{l}\text { Método de } \\
\text { Avaliação* }\end{array}$} & \multicolumn{13}{|c|}{ Departamentos } \\
\hline & \multicolumn{2}{|c|}{$\begin{array}{c}\text { Interdepar- } \\
\text { tamental } \\
(\mathrm{N}=2) \#\end{array}$} & \multicolumn{2}{|c|}{$A(N=5)$} & \multicolumn{2}{|c|}{$B(N=2)$} & \multicolumn{2}{|c|}{$C(\mathrm{~N}=7)$} & \multicolumn{2}{|c|}{$D(N=7)$} & \multicolumn{2}{|c|}{ Total } & \multirow[b]{2}{*}{$\begin{array}{r}\text { Valor- } \\
\mathbf{p}^{\star *}\end{array}$} \\
\hline & $\mathbf{N}$ & $\%$ & $\mathbf{N}$ & $\%$ & $\mathbf{N}$ & $\%$ & $\mathbf{N}$ & $\%$ & $\mathbf{N}$ & $\%$ & $\mathbf{N}$ & $\%$ & \\
\hline $\begin{array}{l}\text { Prova escrita } \\
\text { individual }\end{array}$ & 0 & 0 & 0 & 0 & 2 & 100 & 1 & 14,3 & 1 & 14,3 & 4 & 17,4 & 0,065 \\
\hline $\begin{array}{l}\text { Seminário em } \\
\text { grupo/individual }\end{array}$ & 2 & 10 & 2 & 40 & 0 & 0 & 3 & 42,9 & 4 & 57,1 & 11 & 47,8 & 0,848 \\
\hline $\begin{array}{l}\text { Trabalho em } \\
\text { grupo/individual }\end{array}$ & 1 & 50 & 2 & 40 & 0 & 0 & 4 & 57,1 & 4 & 57,1 & 11 & 47,8 & 1 \\
\hline Estudo de caso & 0 & 0 & 0 & 0 & 0 & 0 & 0 & 0 & 1 & 14,3 & 1 & 4,3 & 0,130 \\
\hline $\begin{array}{l}\text { Participação em } \\
\text { sala de aula }\end{array}$ & 0 & 0 & 5 & 100 & 2 & 100 & 5 & 71,4 & 4 & 57,1 & 16 & 69,6 & 0,142 \\
\hline Autoavaliação & 1 & 50 & 1 & 20 & 0 & 0 & 0 & 0 & 0 & 0 & 2 & 8,7 & 1 \\
\hline Exercícios & 0 & 0 & 0 & 0 & 0 & 0 & 0 & 0 & 0 & 0 & 0 & 0 & 1 \\
\hline Frequência & 1 & 50 & 1 & 20 & 0 & 0 & 3 & 42,9 & 0 & 0 & 5 & 21,7 & 0,233 \\
\hline Outros $^{\star \star \star}$ & 1 & 50 & 1 & 20 & 0 & 0 & 2 & 28,6 & 2 & 28,6 & 6 & 26,1 & 1 \\
\hline
\end{tabular}

Os achados da Tabela 3 apontam que o método participação em sala de aula predominou $16(69,6 \%)$, seguido de $11(47,8 \%)$ representado pelo seminário e trabalho individual ou em grupo.

Ao compararmos os métodos de avaliação aplicados pelos Departamentos, observa-se que no Departamento A, 5 (100\%) e no C $5(71,4 \%)$, os docentes optaram pela avaliação por meio da participação dos discentes em sala de aula. No Departamento D, predominaram o seminário individual ou em grupo e participação em sala de aula $(57,1 \%)$.

\section{Discussão}

Na matriz curricular, organizada em ciclos, módulos e disciplinas há que se manter a preocupação em distribuir equitativamente a carga horária e o quantitativo de disciplinas ao longo dos semestres, além de buscar articulação entre as disciplinas. Os achados deste estudo vão ao encontro dessa premissa, com destaque para articulação interdepartamental, denotando uma inter-relação quanto as diferentes áreas do conhecimento em Enfermagem, favorecendo a aproximação dos saberes, de conteúdos e o relacionamento dos profissionais, envolvidos no ensino de graduação. 
Essas relações possibilitam superar o modelo da racionalidade científica, direcionando a prática do ensino para a construção e a implementação de currículos globalizantes, nos quais os nexos estabelecidos e os saberes ultrapassam a fragmentação disciplinar e propõem a articulação dos conteúdos a partir de projetos, pesquisa, resolução de problemas, de respostas a questões e elaboração de sínteses significativas, de modo a inserir o estudante, com seus limites e possibilidades, no centro dos processos, buscando a construção contínua de sua autonomia (ANASTASIOU; ALVES, 2009).

Outro ponto a destacar diz respeito às formas predominantes de avaliação da aprendizagem na educação superior, uma vez que essas refletem não somente as escolhas pedagógicas dos docentes, mas também as diretrizes curriculares dos cursos, bem como a própria cultura institucional que os influencia (GARCIA, 2009).

Os resultados da presente investigação apontaram que houve homogeneidade na distribuição das disciplinas obrigatórias entre a EEUSP e as UP e ainda, que metade daquelas ministradas na EE foi de cunho departamental. Desse modo, a construção do saber em Enfermagem conta com participação das diferentes áreas conhecimento, representadas por sete UP, a saber: ciências biológicas, humanas, sociais, saúde pública, medicina e psicologia e dos quatro departamentos da própria Escola de Enfermagem.

Outros achados denotaram que de um modo geral as disciplinas integrantes da matriz curricular do Curso de Bacharelado em Enfermagem empregaram mais de um método de avaliação da aprendizagem.

Pesquisa conduzida objetivando conhecer as percepções dos estudantes universitários, acerca dos métodos de avaliação mais utilizados e a relação entre avaliação e aprendizagem, na Universidade do Minho, em Portugal, revelou que os métodos de avaliação empregados pelos docentes interferem, em grande medida, a aprendizagem dos discentes e demonstrou que a maior parte dos alunos $(85,7 \%)$ considerou que a avaliação será mais justa se forem utilizados ao menos dois métodos diferentes de avaliação (RIBEIRO; FLORES, 2012).

Nas disciplinas ministradas pela EEUSP prevaleceram os métodos avaliativos trabalho escrito e a participação em sala de aula, seguidos por seminário e prova escrita nas optativas. $\mathrm{Na}$ comparação entre os métodos utilizados nas disciplinas da EEUSP e das UP, e as disciplinas obrigatórias e optativas na EEUSP, a prova escrita, foi o que apresentou diferença estatística significante, reforçando sua prática nas disciplinas ministradas pelas outras unidades da USP e nas disciplinas obrigatórias da EE. 
O estudo de Ribeiro e Flores (2012) mostrou que os métodos predominantes de avaliação empregados pelos docentes foram as apresentações orais em grupo $(90,9 \%)$, os testes ou exames escritos $(88,6 \%)$, os relatórios realizados em grupo $(86,9 \%)$, retratando o trabalho em grupo e colaborativo. Por outro lado, os menos utilizados corresponderam aos ensaios individuais ou em grupo $(93,7 \%, 81,9 \%)$, aos testes ou aos exames orais $(81,1 \%)$, aos portfólios individuais ou coletivos $(77,1 \%, 70,6 \%)$, prevalecendo nesta categoria métodos relativos ao trabalho individual em detrimento dos que fomentam o trabalho colaborativo dos estudantes.

Ao compararmos os tipos de avaliação entre os departamentos da EEUSP observou-se que não houve diferença estatisticamente significante, exceto para o tipo estudo de caso ou dirigido com $\mathrm{p}=0,07$. No departamento A o critério mais utilizado foi a prova escrita $(100 \%)$ e o departamento $\mathrm{C}$ apresentou maior variabilidade nos tipos de avaliação.

A prova como método visa exclusivamente avaliar conteúdos cognitivos, conceituais e especialmente os factuais, sendo contraindicado para tratar de conteúdos procedimentais e os de caráter atitudinal (ZABALA, 1998). No entanto, ainda possui muitos defensores, sobretudo quando escrita, uma vez que proporciona a liberdade e a espontaneidade de respostas. Em contrapartida, os alunos menos preparados procuram incorporar à dissertação outros temas, embora corretos, podem estar desvinculados do assunto.

A Escola de Enfermagem da USP obteve maior diversidade nos critérios de avaliação com destaque para a autoavaliação, heteroavaliação e portfólio, não encontrados nas disciplinas ministradas pelas UP.

A presença do portfólio, da autoavaliação e da heteroavaliação nos métodos de avaliação da EE-USP, sugere que nas disciplinas desta unidade os docentes têm lançado mão de métodos avaliativos facilitadores da construção, reconstrução e reavaliação do processo ensino-aprendizagem, o que permite uma participação mais ativa do discente, superando a visão pontual dos métodos tradicionais como provas e testes (ALVES, 2009). Esses métodos requerem outras práticas pedagógicas dos docentes e novas atitudes de discentes em relação à aprendizagem e o exercício de estilos de pensamento (GARCIA, 2009).

O portfólio é um tipo de avaliação integrante das metodologias participativas que requerem instrumentos, também, participativos, condizentes com a avaliação formativa, iniciando sua difusão na década de 1990, nas instituições de ensino superior, nos Estados Unidos da América. Como ferramenta de avaliação conduz o estudante a criar e a se responsabilizar pelo seu aprendizado; a participar da formulação dos objetivos de sua aprendizagem e avaliar o seu progresso no decorrer do curso (SANTOS; MIOTTO; 2010). 
Porém, seu êxito depende da sua real aceitação pelos alunos e professores (SANTOS; MIOTTO, 2010; FRIEDRICH et al., 2010).

A autoavaliação oferece ao aluno a oportunidade de desenvolver de forma mais eficiente sua capacidade crítica, permitindo-lhe realizar uma análise própria de seu conhecimento e crescimento pessoal e fazendo-o sentir-se parte integrante do processo (MERINO et al., 2006). Ao ser incluído como método de avaliação no processo pedagógico propicia a participação ativa do aluno no seu desenvolvimento e favorece a reflexão acerca de sua aprendizagem e desempenho, na busca do aperfeiçoamento. Além disso, pode contribuir para a mudança de comportamento, com uma percepção mais responsável de si mesmo, entendendo que o professor não é o único responsável pelo processo de ensino-aprendizagem (KROZETA; MEIER; DANSKI, 2008).

Nas disciplinas optativas, o tipo de avaliação predominante foi à participação em sala de aula, enquanto as disciplinas obrigatórias não empregaram esse critério de avaliação. Tal fato pode estar relacionado ao quantitativo de discentes matriculados e aos objetivos docentes e discentes propostos nos PA dessas disciplinas.

No que tange ao método participação em sala de aula ressaltamos a necessidade para a criação de instrumentos e critérios objetivos, que avaliem a forma de participação do discente, definindo-se, a priori, o como e o que se espera dessa participação.

O seminário em grupo/individual e o trabalho em grupo/individual foram o segundo tipo de avaliação utilizado pelas disciplinas optativas e interdepartamental. O seminário permite ao aluno desenvolver sua capacidade de pesquisa, de produção, de conhecimento, de organização e fundamentação de ideias, bem como elaborar relatórios de pesquisa, fazer inferências e produzir conhecimento de forma coletiva (PRADO et al., 2011).

Constatou-se, ainda, que a participação nas atividades programadas foi o único método de avaliação utilizado por todos os Departamentos da EEUSP, presente em quatro disciplinas da categoria Interdepartamental, duas disciplinas nos departamentos B e C e uma disciplina nos departamentos A e D.

Reiteramos que a participação nas atividades propostas necessita ser monitorada segundo critérios e instrumentos que mensurem objetivamente a qualidade da participação discente na organização e no desenvolvimento das atividades, redirecionando o papel dos alunos e dos professores no processo ensino-aprendizagem (ANASTASIOU, 2009).

Os instrumentos e as posturas frente à avaliação da aprendizagem devem ser amplamente conhecidos e revistos por discentes e docentes que desejam sustentar as mudanças em busca da melhoria da qualidade do ensino (MERINO et al., 2006). 


\section{Conclusão}

Este estudo permitiu constatar que avaliação é um elemento complementar e inseparável do processo ensino-aprendizagem que ultrapassa as dimensões classificatória e reducionista de atribuir notas ou conceitos para a aprovação ou retenção do discente no curso.

Em todos os PA das disciplinas obrigatórias integrantes da matriz curricular do Bacharelado em Enfermagem da EEUSP, assim como, nas disciplinas optativas, esteve descrito um ou mais tipos de avaliação. As disciplinas obrigatórias interdepartamentais ministradas na EE-USP empregaram maior diversidade nos tipos de avaliação, com a inclusão do portfólio.

Nas disciplinas da EEUSP os métodos predominantes de avaliação foram o trabalho escrito e participação em sala de aula e nas UP a prova escrita. Assim, podemos inferir que as disciplinas ministradas pelas UP praticam métodos avaliativos pautados na concepção tradicional da educação, necessitando por parte dos docentes revisões tanto no tipo de avaliação como nas metodologias de aprendizagem dos discentes do Bacharelado em Enfermagem.

Outros tipos de avaliação considerados mais participativos e consonantes a uma proposta curricular globalizante, como a autoavaliação, a heteroavaliação, também, vêm sendo realizadas, ainda que, de maneira incipiente pelas disciplinas ministradas pela EEUSP e nas disciplinas optativas, em menor proporção.

Salientamos para a necessidade de o docente explicitar, claramente, nos PA, os critérios de avaliação, evitando a inespecificidade desses, representada pelas palavras ou expressões como provas, participação nas atividades, avaliação do conhecimento, frequência, dentre outros.

Cabe, ainda, aos docentes questionarem-se acerca da melhor forma de avaliação dos estudantes em função do tipo de aprendizagem requerida, a qual deve estar consonante aos pressupostos do PPP, propiciando aos discentes a experiência de diferentes formas de avaliação da aprendizagem.

Isso posto, acreditamos ser necessário avançar nos estudos sobre os métodos avaliativos na educação superior ultrapassando os modelos tradicionais tanto das metodologias de ensino como do tipo de avaliação da aprendizagem, contribuindo para as transformações requeridas nos cursos de graduação. 


\section{Referências}

ALVES, Leonir Pessate. Portfólios como instrumentos de avaliação dos processos de ensinagem. In: ANASTACIOU, Lea das Graças Camargo; ALVES, Leonir Pessate (Orgs.). Processos de ensinagem na universidade: pressupostos para as estratégias de trabalho em aula. 8. ed. Joinvile: Univille, 2009. p. 110- 129.

ANASTASIOU, Lea das Graças Camargo. Da visão de ciênia à organização curricular. In: ANASTASIOU, Lea das Graças Camargo; ALVES, Leonir Pessate (Orgs.). Processos de ensinagem na universidade: pressupostos para as estratégias de trabalho em aula. 8. ed. Joinville: Univille, 2009. p. 40-63.

ANASTASIOU, Lea das Graças Camargo; ALVES, Leonir Pessate (Orgs.). Processo de ensinagem na universidade: pressupostos para as estratégias de trabalho em aula. 8. ed. Joinvile: Univille, 2009.

BRACCIALLI, Luzmaria Aparecida Doretto; OLIVEIRA, Maria Amélia Campos. Desafios na formação médica: a contribuição da avaliação. Revista Brasileira de Educação Médica, Rio de Janeiro, v. 36, n. 2, p. 280-288, 2012.

DIAS, Denise Costa; MUROFUSE, Neide Tiemi; SCHNEIDE, Jacó Fernando; TONINI, Nelsi Salete; OLIVEIRA, Beatriz Rosana Gonçalves. Reflexões sobre o desafio da administração da educação em enfermagem. Revista Brasileira de Enfermagem, Brasília, v. 57, n. 4, p. 490-492, 2004.

FRANCISCO, Anete Maria; COSTA, Maria Cristina Guimarães da; HAMAMOTO, Cássia Galli; HAFNER, Maria de Lourdes M. Botta. Avaliação da formação de enfermeiros: o reflexo dos métodos de ensino-aprendizagem e pressupostos curriculares na prática profissional. Avaliação, Campinas; Sorocaba, v. 21, n. 2, p. 479-502, 2016.

FRIEDRICH, Denise Barbosa de Castro; GONÇALVES, Angela Maria Corrêa; SÁ, Tatiana Santos; SANGLARD, Letícia Ribeiro; DUQUE, Débora Ribeiro; OLIVEIRA, Gabriela Mota Antunes. O portfólio como avaliação: análise de sua utilização na graduação de enfermagem. Revista Latino-Americana de Enfermagem, Ribeirão Preto, v. 18, n. 6, p. 1123-1130, 2010. GARCIA, Joe. Avaliação e aprendizagem no ensino superior. Rev Est. Aval. Educ., São Paulo, v. 20, n. 43, p. 201-213, 2009.

KROZETA, Kara; MEIER, Marineli Joaquim; DANSKI, Mitzy Reichembach. A autoavaliação: uma possibilidade de mudança na formação profissional. Cogitare Enfermagem, Curitiba, v. 13, n. 4, p. 612-615, 2008.

LALUNA, Maria Cristina Martinez Capel; FERRAZ, Clarice Aparecida. Finalidades e função da avaliação na formação de enfermeiros. Revista Brasileira de Enfermagem, Brasília, v. 60, n. 6, p. 641-645, 2007.

MERINO, Maria de Fátima Garcia Lopes; HIGARASHI, Ieda Harumi; CARVALHO, Maria Dalva de Barros; PELLOSO, Sandra Marisa. Instrumentos e técnicas avaliativas de estudantes de enfermagem. Ciência, Cuidado e Saúde, Maringá, v. 5, n. 2, p. 147-157, 2006.

PRADO, Cláudia; PEREIRA, Irene Mari; FUGULIN, Fernanda Maria Togeiro; PERES, Heloísa Helena Ciqueto; CASTILHO, Valéria. Seminários na perspectiva dialética: experiência na disciplina Administração em Enfermagem. Acta Paulista de Enfermagem, São Paulo, v. 24, n. 4, p. 582-585, 2011.

PÜSCHEL, Vilanice Alves de Araújo. A mudança curricular do bacharelado em Enfermagem da Escola de Enfermagem da USP: análise documental e vivência dos 
participantes. 2011. 269p. Tese (Livre-Docência) - Escola de Enfermagem da Universidade de São Paulo, São Paulo, 2011.

RIBEIRO, Diana Pereira; FLORES, Maria Assunção. Percepções dos estudantes universitários sobre a avaliação das aprendizagens: um estudo exploratório. Avaliação, Campinas; Sorocaba, v. 17, n. 2, p.529-555, 2012.

SANTOS, Fabiana Lora; MIOTTO, Luciana Bernardo. Portfólio: novas perspectivas para avaliação escolar. Cuidado Arte Enfermagem, Catanduva, v. 4, n. 1, p. 21-30, 2010.

VASCONCELOS, Claudinete Maria da Conceição Bezerra; BACKES, Vânia Marli Schubert; GUES, Jussara Martini. Avaliação no ensino de graduação em enfermagem na América Latina: uma revisão integrativa. Enfermería Global, Murcia, n. 23, p. 118-39, 2011.

UNIVERSIDADE DE SÃO PAULO. Escola de Enfermagem da USP. Projeto Político Pedagógico do Bacharelado em Enfermagem. São Paulo, 2011.

ZABALA, Antoni. A prática educativa: como ensinar. Porto Alegre: Artmed, 1998.

\author{
Daisy Rizatto Tronchin - Universidade de São Paulo, Escola de Enfermagem \\ São Paulo | SP | Brasil. Contato: daisyrtronchin@gmail.com \\ Aisha Negreiros da Costa Pedro - Universidade de São Paulo, Escola de Enfermagem \\ São Paulo | SP | Brasil Contato: aisha.pedro@usp.br \\ Daniele Pereira Rezende - Universidade de São Paulo, Escola de Enfermagem \\ São Paulo | SP | Brasil Contato: daniele.rezende@usp.br
}

Artigo recebido em 23 de novembro de 2017 e aprovado em 24 de novembro de 2017.

\title{
ERRATA
}

No artigo: Métodos avaliativos da aprendizagem no bacharelado na Escola de Enfermagem da Universidade de São Paulo, doi: 10.1590/s1414-40772017000300010, publicado na Revista da Avaliação da Educação Superior (Campinas), de novembro de 2017, volume: 22, número: 3, na página 758 onde se lê apenas o nome da autora: Daisy Rizatto Tronchin, deve-se incluir os nomes das autoras: Aisha Negreiros da Costa Pedro e Daniele Pereira Rezende, todas da Universidade de São Paulo, Escola de Enfermagem. 